\title{
LAS PARADOJAS FINANCIERAS DEL ABASTECIMIENTO DE LARACHE Y MAMORA: PRESIDIOS, LOGÍSTICA MILITAR Y ARISTOCRACIA, 1611-1635
}

\author{
Luis Salas Almela \\ Universidad de Córdoba
}

RESUMEN. Este artículo analiza en primer lugar las circunstancias que condujeron a que la vigilancia y mantenimiento de los presidios de Larache y Mamora quedasen vinculadas desde su conquista —en 1611 y 1614 respectivamente - hasta 1641 a los duques de Medina Sidonia. A lo largo de este periodo, la falta de concreción administrativa de este cometido asumido por los aristócratas andaluces fue el origen de conflictos y fricciones con la corte regia que pusieron de manifiesto la paradójica situación creada, según la cual cuanto mayor era la autonomía de mando que iban alcanzando los duques, mayor era el esfuerzo económico que les suponía, pese a sus reiteradas demandas para que se encontrase una solución financiera estable. Así mismo, se analizan algunos expedientes que se ensayaron para tratar de alcanzar un equilibrio. Una serie de esfuerzos que el experimento de la contribución única de la sal terminó obligando a abandonar en 1631-1635.

Palabras clave: defensa, frontera, presidios, Magreb, aristocracia

ABSTRACT. In the first place, this article analyses the circumstances that caused that the Ducal House of Medina Sidonia became responsible for the surveillance and maintenance of the presidios of Larache and Mamora since these two African outposts were conquered -in 1611 and 1614 respectively- until 1641. Throughout this period, the lack of administrative concreteness of the role played by the Andalusian dukes was a source of conflicts and frictions with the Royal Court. A situation that highlighted the paradoxical situation created: the greater the command autonomy over the presidios was effortlessly being achieved by the Medina Sidonia's, the greater this meant a financial effort for their own treasury, despite their repeated demands for a stable royal financing system. Finally, the article sheds light on some attempts to create an equilibrium that the fiscal revolution based on the salt finally blew up in 1631-1635.

Keywords: defence, border, outpost, Maghreb, aristocracy

Recibido: 13-11-2020.Aceptado: 18-3-2021.. Isalmela@uco.es 


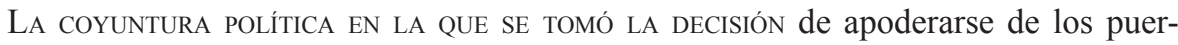
tos de Larache y Mamora ha sido suficientemente descrita y analizada en el doble contexto de la Tregua de los Doce Años y de la expulsión de los moriscos. Esto ha implicado que la decisión se haya interpretado como consecuencia de la necesidad de protección del lado occidental del estrecho de Gibraltar frente al acoso constante del corsarismo - tanto magrebí como europeo, sobre todo holandés e inglés-, por un lado, mientras que en términos de política exterior de la Monarquía Hispánica se ha interpretado como una forma de recuperar el prestigio perdido en el norte de Europa, precisamente a causa de la tregua con los holandeses. Todo ello en un contexto donde la posibilidad de que alguno de los enemigos europeos se hiciese con un puerto en Marruecos era moneda corriente en los contactos diplomáticos con los herederos del gran sultán sa'adí Almansur (Alcalá-Zamora, 1976; Allen, 2000; Israel, 1997, pp. 34 35; García, 1996; Saldanha de Albuquerque, 1997). Siendo perfectamente válido este esquema a los efectos que aquí nos interesan, es muy poco lo que sabemos en cambio sobre estos presidios en los primeros años de dominación castellana, en particular en lo que atañe a los aspectos logísticos y financieros de su mantenimiento (Díez, 1928; García Figueras y Rodríguez Jouliá Saint-Cyr,1973; Sancho de Sopranis; Bueno Soto, 2008; Bunes Ibarra, 2011). En este trabajo vamos a estudiar las dificultades que implicó sostener unos enclaves ubicados en territorio hostil y cuya integración en los dominios de los Austrias madrileños se produjo en un momento en que las reservas para la guerra comenzaban a escasear.

\section{El peso de una nueva frontera: la Baja Andalucía y los presidios}

Tras la toma de posesión de los presidios de Larache y Mamora se abrió de inmediato el reto de intentar evitar su pérdida. Ello implicaba dos tipos de procesos: por un lado, la fortificación de las plazas y, por otro, crear ex novo un sistema de suministro de bastimentos y reemplazo de tropas. La primera cuestión ha sido analizada con cierto detalle y no es la que más directamente nos incumbe aquí (Bueno Soto, 2008). Nuestro análisis se va a centrar en determinar cómo se lograron mantener abastecidas las nuevas posesiones desde la Península Ibérica puesto que, al igual que había ocurrido con los presidios castellanos en las costas mediterráneas del Magreb, Larache y Mamora padecieron un acusado aislamiento de su entorno geográfico, especialmente hostil en los primeros años de ocupación. En este sentido, hay que tener en cuenta que la posesión de todos estos enclaves fue el resultado de la necesidad de limitar las actividades corsarias y proteger las rutas mercantiles, tanto en el Mediterráneo como en el área atlántica. Expresado en términos económicos, esto implicaba que cada nuevo 
presidio computaba casi en exclusiva en el pasivo de la monarquía como gasto que, solo indirectamente, se veía compensado por el daño que se evitaba al comercio. La mayor diferencia entre los dos lados del Estrecho es que, en el caso de los presidios mediterráneos, el mantenimiento quedó canalizado desde el siglo XVI por medio de la proveeduría general de presidios radicada en Málaga, lo cual garantizó unos mínimos de estabilidad (Jiménez Estrella, 2004; Alonso Acero, 2007).

En efecto, cuando se incorporaron Larache y Mamora a los dominios de Felipe III no se previó ningún mecanismo específico para su sostenimiento. Esto no quiere decir, sin embargo, que Lerma no tuviese claras las líneas maestras de cómo se habían de integrar, al menos de momento, los nuevos presidios en el organigrama militar de la monarquía. Un planteamiento general que quedó de manifiesto ya en la reunión del consejo de Estado en la que se recibió oficialmente en Madrid la noticia de la pacífica toma de Larache por el marqués de San Germán (Feros, 2002, p. 415)ํ․․ Tras la lectura del relato y el reparto de elogios por parte de los consejeros a los aristócratas partícipes en la acción, Lerma, además de sumarse a las alabanzas, introdujo en las gratitudes el nombre de su consuegro, el duque de Medina Sidonia, a la sazón capitán general del Mar Océano y Costas de Andalucía (Salas Almela, 2002). Demostrando que su preocupación trascendía lo más inmediato, añadió:

que al duque de Medina Sidonia se le escriba agradeciéndole el cuidado con que ha ayudado a lo que le ha tocado y diciéndole que Vuestra Majestad espera de él en esta ocasión lo que suele en todas y es que se tendrá por muy servido de lo que haga asistir y socorrer al marqués, de manera que no le falte lo forzoso; que también se escriba al asistente de Sevilla y corregidores de Cádiz, Gibraltar y los responsables de las fronteras que acudan con lo necesario ${ }^{2}$.

Quedaba así dibujado el esquema por medio del cual se esperaba sostener una plaza — Larache, a la que en 1614 se sumó en similares términos Mamora- que se incorporaba en las posesiones de la monarquía bajo el signo de la precariedad y la emergencia. Los referentes geográficos, institucionales y urbanos mencionados por el valido son bien significativos: los nuevos presidios se integraban en Castilla como avanzadillas de la Baja Andalucía ${ }^{3}$. Ahora bien, más en concreto lo único que esto dejaba claro era que el capitán general de la costa atlántica andaluza - Medina

1 Don Juan Hurtado de Mendoza (marqués de San Germán), sobrino y hombre de confianza de Lerma, tras su regreso de la embajada en Londres desempeñó cargos en la Baja Andalucía. Archivo General Fundación Casa de Medina Sidonia (en adelante AFCMS), leg. 2.407, 22 de agosto de 1607.

2 Archivo General de Simancas (en adelante AGS), Estado, leg. 494, sin número, consulta de 27 de noviembre de 1610

3 AGS, Guerra Antigua, leg. 729, consulta a partir de una carta del Marqués de San Germán sobre la fuerza que quedaría en Larache, 9 de diciembre de 1610 
Sidonia - sería quien organizase el suministro de los presidios, mientras que debían ser las ciudades de Sevilla, Cádiz y Gibraltar las que proveyesen los hombres y bastimentos necesarios para ello ${ }^{4}$. Esta dejación de funciones, al menos en principio, se ajusta al esquema explicativo que planteó Thomson respecto a la participación de la aristocracia castellana en los ejércitos de la Monarquía Hispánica desde fines del XVI, aunque veremos que con algunos matices (Thompson, 1981, pp.181-197).

Más allá de la lógica geográfica a la que responde el planteamiento de Lerma, es importante detenernos un instante a analizar las causas por las que el valido quiso implicar a las principales ciudades de la región en el esfuerzo de sostener las nuevas posesiones de Felipe III. La razón más directa radica en que eran dichas ciudades, y la costa atlántica andaluza en general, las que más padecían una actividad corsaria que dañaba mucho el comercio no solo en términos de presas directas, sino por el aumento de costes que implicaba cualquier operación de transacción marítima por el factor riesgo. Es decir, a diferencia de la costa granadina, donde la relativa incomunicación de muchas poblaciones aumentaba el riesgo de padecer ataques a mayor escala, en la costa atlántica el mayor daño lo padecían los buques mercantes de pequeño y mediano porte. No obstante, ni todas las escalas del comercio eran equiparables ni a largo plazo la amenaza corsaria se dejó sentir del mismo modo. Así, si bien el sistema oficial de flotas convoyadas de la Carrera de Indias quedaba en principio fuera del alcance de los corsarios, no ocurría otro tanto con los frecuentes viajes transoceánicos de barcos sueltos, en los que también circulaban mercancías valiosas y ocasionalmente altos oficiales de la monarquía. En todo caso, el efecto de las tomas de Larache y Mamora fue empujar a los corsarios unas millas hacia el sur, lo que protegió algo más el comercio de cabotaje peninsular, pero en cambio produjo una concentración de todo el potencial del corso atlántico magrebí - local, morisco, europeo y tunecino- en la que pronto se iba a erigir como república corsaria de Salé. Una situación que, a su vez, permitió a los corsarios operaciones de tal envergadura que alcanzaron incluso Islandia. En estas circunstancias, cualquier objetivo podía ser susceptible de captura para los corsarios, de forma que los grandes centros mercantiles de la Baja Andalucía quedaron plenamente concernidos por el auge del corsarismo y los remedios que se tratasen de aplicar.

De una naturaleza algo distinta es el interés que el VII duque de Medina Sidonia mostró por los presidios africanos. Conviene recordar que el duque venía fijando su atención en Larache desde la batalla de Alcazarquivir de 1578. Décadas después, ya desaparecido Almansur en 1603, el duque propuso de nuevo un plan de conquista 
de la plaza que se discutió en 1606-16075. De igual modo, tras la incorporación del presidio, cuando se comprobó que el corso se había trasladado a Mamora, Medina Sidonia fue uno de los principales partidarios de conquistar también esta otra plaza frente a quienes abogaban por limitar la acción de la monarquía a una expedición de castigo contra ella ${ }^{6}$. En parte, claro está, la condición del duque de señor jurisdiccional de la mitad de la costa de su distrito militar - que abarcaba de Gibraltar a la desembocadura del Guadiana- le hacía tener un interés muy directo en la seguridad de las aguas, máxime si atendemos a la dependencia que sus ingresos tenían de las rentas devengadas del comercio (Salas Almela, 2008, pp. 221-251). Al mismo tiempo, tomar la iniciativa en aquella frontera consolidaba el prestigio que le confería ser defensor de la patria y de los intereses de Sevilla como capitán general de la costa. Es importante no perder de vista además que desde la década de 1570 el duque había desarrollado una poderosa red de informantes en el interior de Marruecos, de modo que en la década de 1610 su influencia en aquella región alcanzaba de lleno el plano diplomático, trascendiendo la labor de gestor para convertirse en asesor preferente sobre el Magreb (García-Arenal et al., 2002, pp 47-68).

Desde otro punto de vista, las incertidumbres iniciales respecto a la financiación del sostenimiento de los nuevos presidios provocaron inquietud en los ministros de la corona de Portugal, que temían que la irrupción de la presencia castellana en la costa atlántica del Magreb pusiese en riesgo los presidios lusos en aquella región, dado lo exiguo de los medios disponibles ${ }^{7}$. Ciertamente, ante los más que previsibles problemas, los consejeros de Felipe III no tenían otro plan de contingencia que recurrir a la capacidad logística de Medina Sidonia. Así, cuando aún se estaban ultimando los planes de conquista de Mamora, el secretario del consejo de Guerra, Martín de Aróztegui lo expresó con claridad al señalar que, «como he dicho otras veces, para Vuestra Excelencia no hay cosa imposible de las que con medios humanos se pueden ${ }^{8}$. No eran palabras vanas aquellas: según reconocía en una consulta el consejo de Estado, la mayor parte de las tropas que se apoderaron de Mamora procedieron de la Baja Andalucía, quintadas y puestas en armas por Medina Sidonia9. Más aún, unos meses después el duque tuvo que anticipar ya el dinero necesario — hasta 224.219 reales $^{10}$ — para sostener la flamante conquista. Según denunció el conde de Salvatierra - asistente de Sevilla_-, la falta de previsión había llevado a unas lamentables condiciones a las milicias de la ciudad que habían participado en la toma del presidio, pese a lo cual el propio cabildo hispalense se negó a prestar ayuda pretextando no te-

5 AFCMS, leg. 2.406, 4 de noviembre de 1606 y leg. 2.407, 15 de agosto de 1607.

6 AFCMS, leg. 2.409, 14 de marzo de 1614.

7 AGS, Estado, 2.644, n. 53, 3 de febrero de 1614

8 AGS, Guerra Antigua, leg. 790, 28 de noviembre de 1614.

9 AGS, Estado, leg. 2.644, n. 51, consulta de 19 de agosto de 1614.

10 AGS, Guerra Antigua, leg. 790, 16 de noviembre de 1614. 
ner orden del rey para ello. Por su parte, el consejo de Estado entendió que, con aquella iniciativa, Salvatierra estaba tratando de asumir competencias en materia militar que no le correspondían, de modo que remitió toda la cuestión a Medina Sidonia ${ }^{11}$. Con ello se quería dejar claro que de Sevilla y de su amplio hinterland se esperaba que pusieran los medios, pero la gestión debía correr a cargo del duque, quizá como forma de hacer atractiva al propio don Alonso una nueva situación que ya comenzaba a pesar sobre sus propios recursos.

Sea como fuere, sin que tengamos constancia de las fechas precisas, sabemos que en los meses posteriores a la conquista de Mamora la provisión de ambos presidios se integró en la contabilidad genérica de las Contadurías Mayores, aunque sin asignación presupuestaria, bajo el mismo rubro que los presidios de la Andalucía atlántica, entre los que se contaban Cádiz y Gibraltar. Es decir, institucionalmente no se produjo otra novedad que la creación de una teneduría de bastimentos específica para Larache y Mamora radicada en El Puerto de Santa María y bajo la dependencia del proveedor general de Andalucía, con sede en Sevilla. En 1623 todavía ocupaba este último cargo Gregorio Muñoz de Medrano — nombrado como tal en 1610-, el cual se dirigió entonces al rey pidiendo un aumento de su salario recordando que, tras la conquista de Larache, siendo él militar reformado, se le reintegró en el servicio activo como tenedor de bastimentos, si bien al estar su residencia en Sevilla se le permitió nombrar un teniente que ejerciese en El Puerto - Francisco Sánchez- el cual fue aceptado por el proveedor general de Andalucía, Luis Sáenz de Oyanguren ${ }^{12}$. De esta forma, se normalizó la supervisión contable y de la calidad de los bastimentos remitidos pero en cambio la financiación del sistema quedaba todavía al albur de que las partidas genéricas que proporcionase la Contaduría Mayor para los presidios de Andalucía pudiesen llegar a cubrir las necesidades de los presidios.

\section{Las paradojas de una dependencia institucional y personal}

La combinación de la capacidad de Medina Sidonia para cubrir emergencias con la falta de recursos financieros estables creó un espacio de incertidumbre que se reveló muy conflictivo. Una de las últimas decisiones en las que el VII duque de Medina Sidonia intentó, sin lograrlo, hacer valer toda su influencia en la corte antes de su fallecimiento fue «asentar con el señor presidente de Hacienda la provisión de las fronteras», puesto que un lustro después de la toma de Larache no había atisbo

11 AGS, Estado, leg. 2.644, n. 56, 6 de septiembre de 1614.

12 A Francisco Sánchez se le señaló un sueldo de 4 reales al día, cantidad bastante inferior de la habitual -10 o 12 reales_-, sueldo que además debía abonar el propio Muñoz Medrano. AGS, Guerra Antigua, leg. 888, consulta de 23 de marzo de 1623, 
de solución ${ }^{13}$. Lo que pretendía el viejo duque no era nada nuevo, puesto que los presidios mediterráneos ya contaban con partidas estables desde hacía dos décadas (Alonso Acero, 2000, pp. 320-365). En los últimos días de julio de 1615 fallecía el VII duque de Medina Sidonia, siendo sucedido en su casa, herencia y cargos militares por su hijo Manuel Alonso. El VIII duque no carecía tampoco de experiencia de mando, puesto que más allá de llevar unos años con casa propia y gobernando parte de la herencia familiar — el condado de Niebla_, entre 1603 y 1606 había sido capitán general de las galeras de España, de modo que conocía bien el funcionamiento y las fallas de la provisión militar ${ }^{14}$. Una experiencia que le iba a resultar muy útil para afrontar el cuidado de unos presidios cuya responsabilidad asumió sobre la base de ciertos resortes formales e informales que, a su vez, eran resultado del compromiso personal asumido por su padre desde la ocupación de Larache.

Ciertamente la precariedad no era exclusiva de los nuevos presidios africanos ni, en puridad, del ámbito hispánico. La inexistencia de una política presupuestaria propiamente dicha en aquella época generaba carencias que se dejaban sentir en todos los órdenes de inversión de los dineros de reyes, reinos y repúblicas (Alfani y Di Tullio, 2019, pp. 165-174). No obstante, en el caso español y, más en concreto, para los presidios africanos, podemos identificar escalas diferenciadas para este problema generalizado (Bunes Ibarra, 1988; Alonso Acero, 2001). Así, cuando por alguna circunstancia las fortalezas mediterráneas que tenían asignada una partida teórica en los gastos ordinarios padecían una situación crítica porque los fondos no llegaban, las soluciones resultaban relativamente más sencillas puesto que, al menos, el cauce institucional existía y solo había que buscar una partida saneada. Fue, por ejemplo, lo que sucedió en 1617 en Gibraltar, cuando la orden de provisión de los fondos señalados por el consejo de Guerra no fue seguida por la libranza que debía ordenar el de Hacienda, lo que provocó una situación complicada, aunque pasajera ${ }^{15}$. Por contraste, en el caso de Larache y Mamora, al no existir una partida específica, cada libranza se debía obtener presionando al consejo de Hacienda para que librase un dinero cuya escasez tendió a agravarse desde que la intervención en la guerra de los Treinta Años expandió enormemente el gasto militar. Ya en enero de 1621 el consejo de Guerra recordó a su homólogo de Hacienda que en los últimos meses había llegado a consultar 21 veces sobre la financiación de los presidios, sin obtener respuesta ${ }^{16}$. Así las cosas, al VIII duque se le abrían dos posibilidades para evitar que los presidios cayesen en manos enemigas: o bien recurrir a la ambigüedad de sus atribuciones para, extrali-

13 AFCMS, leg. 2.410, carta de Bartolomé de Anaya al duque de Medina Sidonia, 22 de julio de 1615.

14 AGS, Varios Medina-Sidonia, caja 4, n. 56, publicado en Colección de Documentos Inéditos para la Historia de España (1856, t. 28, pp. 393-424).

15 AGS, Guerra Antigua, leg. 817, 29 de noviembre de 1617.

16 AGS, Guerra Antigua, leg. 864, 11 de enero de 1621. 
mitándose, echar mano de partidas no destinadas a tal fin; o bien adelantar él mismo los fondos en la esperanza de poder resarcirse más adelante. En 1619 se le reprochó haber utilizado fondos de titularidad regia sin libranza específica del consejo de Hacienda, argumento frente al cual el duque se defendió recordando cómo, por servir al rey, «certifico a vuestra merced que no rehuso gastar el [dinero] mío en su real servicio, que bien sé las obligaciones con que nací» ${ }^{17}$.

Por otra parte, el ascenso al trono de Felipe IV y los aires reputacionistas del nuevo gobierno de la monarquía abrieron para Medina Sidonia la esperanza de alcanzar un acuerdo estable para los presidios. Apenas unos meses después de haber accedido al trono, el rey agradeció al duque haber asegurado Larache con el envío de 200 hombres, vasallos del propio duque y levantados y armados a su costa, para reforzar la plaza en un momento de especial inquietud por las amenazas que padecía. En palabras del monarca, refiriéndose a este servicio, aseguró que «tendré memoria de él en todo lo que os tocare, como lo merece también vuestro buen celo y el cuidado y desvelo» ${ }^{18}$. Unos meses después, aprovechando aquella gratitud, el duque propuso en el consejo de Guerra la firma de un asiento con ciertos mercaderes que se comprometían a proveer los presidios por un precio de 50 maravedís por ración durante ocho años. Aunque con mucho retraso, el consejo se hizo eco de la propuesta, lo que supone que por primera vez se debatió en la corte la estabilización de la provisión de los presidios atlánticos castellanos ${ }^{19}$. Por razones que no conocemos, la propuesta no prosperó. El secretario Anaya — siempre muy servicial con Medina Sidonia - expresó su desconcierto al afirmar que «certifico a Vuestra Excelencia que he perdido el norte en la materia de provisión de dinero» ${ }^{20}$. Como consecuencia, un año después del socorro con sus 200 vasallos, Medina Sidonia tuvo que volver a cubrir necesidades de los presidios mediante el envío de 1.000 barriles de atún de sus almadrabas cuyo coste trató de cobrar en plata del proveedor de los presidios de Andalucía ${ }^{21}$. Esta última solución es bien significativa de las múltiples ramificaciones que las ambigüedades del sistema generaban, puesto que mezclaba intereses señoriales y de servicio al rey de forma inextricable. Así, si bien desconocemos por qué precisamente ese año Medina Sidonia quiso emplear atún de sus almadrabas para proveer los presidios, es evidente que el mecanismo de adelantar los socorros necesarios amparado en la urgencia abría enormes posibilidades de colocar producción propia agropecuaria o piscatoria.

17 AFCMS, leg. 2.411, 4 y 12 de septiembre de 1619.

18 AFCMS, leg. 2.411, 8 de junio de 1621.

19 Los mercaderes eran Alonso de Terán, vecino del Puerto de Santa María y el asturiano Fernando de Cubián. AFCMS, leg. 2.411, 28 de diciembre de 1621 y 15 de marzo de 1622. Sobre la naturaleza de los contratos de asientos, (véase Domínguez Ortíz, 1960, pp. 92-95).

21 AFCMS, leg. 2.986, carta de los agentes en Sevilla, 27 de julio de 1622. 
Ahora bien, esta fórmula de situar stock a cuenta de los dineros del rey tenía un escollo en los ministros de la proveeduría general de Andalucía, que con frecuencia ponían objeciones y cuya intervención, como mínimo, implicaba retrasos. A mediados de la década de 1620 los cargos concernidos los ocupaban Luis Sanz de Oyanguren como proveedor - el cual comenzó su carrera como contador en Andalucía en $1614^{22}$ - Martín de Portu como pagador, Juan de Otáñez como veedor y Francisco Sánchez Márquez como tenedor de bastimentos. Tras el éxito de todo el sistema defensivo de la Baja Andalucía que supuso el rechazo del asalto inglés a Cádiz de 1625, Medina Sidonia aspiró a reorganizar este engranaje poniéndolo bajo su control directo con el argumento de que la experiencia del ataque había demostrado la utilidad de que el veedor y el pagador abandonasen El Puerto de Santa María para servir junto a él. En carta al secretario Pedro de Arce el duque expuso «las conveniencias que se siguen de asistir en Sanlúcar estos oficiales reales», para lo que remitía certificación de lo eficazmente que se había trabajado. En cambio, si hubiesen continuado en El Puerto «hubieran estado ociosos por no haberse despachado cosa alguna en aquella ciudad». En definitiva, según él, Sanlúcar era el lugar más conveniente para estos oficiales al ser el más seguro de la costa. Con estos argumentos el duque encargó a Arce que defendiese en los consejos de Estado y Guerra la reforma, rechazando de paso otras propuestas que se habían planteado. Una de ellas consistía en la supresión de los ministros específicos para los presidios de Larache y Mamora para que sus funciones las asumiesen los proveedores de Cádiz. A esta opción respondió el duque señalando que si tal cosa se implementaba, o bien descuidarían el presidio gaditano o bien se les tendría que encontrar sustitutos con mucha frecuencia para atender los presidios africanos, lo que implicaría nuevos gastos. Aunando los argumentos de gratitud debida y eficacia, insistía el duque diciendo que:

\begin{abstract}
continuamente se ofrecen aquí [en Sanlúcar] muchos despachos que tocan a fronteras, en que no tienen parte los oficiales reales del presidio, sino los de las provisiones de Andalucía, que ocupándolos en ellos no causan costa y se emplean en servicio de Su Majestad. [...] No hallo razón que contradiga las que me obligaron a detenerlos [al veedor y pagador] aquí, ni sé el fundamento que tiene el mandarme que los envíe a El Puerto porque asistan al proveedor, pues yo los llamo para buscar arbitrios y a mi crédito, lo que debía buscar al suyo quien tiene esta obligación por proveedor de las fronteras y se halla libre de ella mediante mi cuidado ${ }^{23}$.
\end{abstract}

Pese al contundente argumento del esfuerzo financiero asumido por él mismo, Felipe IV ordenó la vuelta de estos ministros a su lugar habitual, si bien, lejos de reprender a Medina Sidonia, le agradeció las gestiones realizadas durante el ataque

22 AGS, Estado, 2.644, n. 16, nombramiento de Oyanguren, marzo de 1614.

23 AFCMS, leg. 2.413, 25 de octubre de 1626. 
inglés. Además, el monarca le ofrecía la posibilidad de que «si a vos os pereciere que por uno o dos meses es menester que asista en Sanlúcar el veedor a acabar de dar los recaudos que faltaren o a otros efectos de mi servicio, daréis orden para que lo haga, pero acabados se ha de volver a El Puerto de Santa María». En caso de emergencia, la real orden autorizaba a recurrir al veedor o al contador, a elección del duque, para que asistiesen junto a él ${ }^{24}$. De este modo, si bien es cierto que Medina Sidonia no logró su objetivo de máximos, al menos asentó en ambos consejos dos ideas fundamentales: por una parte, que en caso de emergencia su autoridad militar debía asumir también el sistema de aprovisionamiento; por otra parte, se admitía que dicho sistema necesitaba reforma, en buena medida porque si al proveedor de bastimentos no se le proporcionaban fondos regios, su cometido carecía de virtualidad, como denunciaba el duque en su escrito.

Así pues, independientemente de las oportunidades coyunturales que en un momento $\mathrm{u}$ otro se abriesen al duque para amortiguar el gasto asumido, lo cierto es que la falta de financiación específica perpetuaba un estado de emergencia que en nada favorecía a los presidios mismos. La descripción de la situación que hizo en enero de 1626 el gobernador de Larache en una carta dirigida a Felipe IV es desoladora. Señalaba el gobernador que acababan de recibir socorros remitidos por Medina Sidonia, pero que en las semanas anteriores los soldados habían llegado a comerse los perros y caballos que iban muriendo para no perecer de hambre. Una carestía de la que, decía, había dado cuenta al rey y a Medina Sidonia en 31 despachos de los que no había obtenido respuesta por parte del soberano, ni por vía de Guerra ni de $E_{\text {Estado }}{ }^{25}$. Después de que, tras una década de gobierno del VIII duque, la situación no hubiese variado mucho, cabe preguntarse hasta qué punto estaba dispuesta a implicarse la casa de Medina Sidonia en esta empresa, ya que en la medida que podamos afinar nuestra respuesta estaremos siendo capaces de entender mejor el equilibrio de intereses, variable sin duda, que venimos describiendo. En este sentido, conviene tener en cuenta que la tensión institucional entre la corte y la capitanía del duque por esta causa se libraba en un terreno que no era desde luego solo financiero, sino que sobre él también pesaba mucho un intangible como es el crédito social. Al fin y al cabo, por mucho prestigio que el cuidado Larache y Mamora reportase a la casa ducal, si las plazas llegaban a perderse el resultado de tanto esfuerzo podía tornarse en deshonra para los Medina Sidonia. En buena parte por eso, tanto el VIII como el IX duques — este último en los pocos años que fue capitán general de la costaperseveraron en el empleo de sus recursos en enormes cantidades para sortear las peores amenazas para los presidios y para sí mismos. Cualquier solución al dilema se presentaba así difícil y costosa.

24 AFCMS, leg. 2.413, dos cartas de Felipe IV a Medina Sidonia de 4 de febrero de 1627.

25 AGS, Estado, leg. 2.645, consulta de 7 de abril de 1626. 
En el contexto de mediados de la década de 1620, relativamente favorable a sus demandas, Medina Sidonia presentó también algunas otras propuestas —una de ellas, por ejemplo, basada en una reforma del sistema de redención de cautivos - para que los presidios se pudiesen autofinanciar (Salas Almela, 2008, pp. 275-278). La idea de la autonomía financiera de los presidios no era en absoluto original, como tampoco lo era la de aprovechar para ello los márgenes de beneficio que el rescate de cautivos generaba (Hershenzorn, 2018, pp. 41-67). Ya en 1614 el VII duque había propuesto alcanzar ese objetivo por medio de los rendimientos fiscales que podía reportar abrir una ruta comercial entre Larache y Andalucía, o mejor aún para él, entre Sanlúcar y Larache. La cuestión presentaba sin embargo diversos problemas. Por un lado, la contradicción que se producía entre la exclusividad fiscal que se venía atribuyendo al ramo del almojarifazgo de Berbería, cuya sede tradicional era Cádiz. Por otro lado, la posibilidad de un comercio de cierta envergadura dependía mucho del grado de aislamiento que padeciesen los presidios con respecto al entorno magrebí, lo que a su vez dependía de los equilibrios diplomáticos establecidos entre los diversos poderes marroquíes entre sí y con la Monarquía Hispánica.

A pesar de ello, había múltiples fórmulas para introducir un comercio que podría contribuir a aliviar la carga que Medina Sidonia había asumido con Larache y Mamora. El 15 de febrero de 1625 Felipe IV aprobó una propuesta de Medina Sidonia consistente en abrir relaciones comerciales entre Mamora y la república corsaria de Salé, por entonces ya gobernada por los moriscos de Hornachos ${ }^{26}$. Seis años después, Medina Sidonia explicó que aquella genérica autorización del rey había sido interpretada por él como un aval «que permite el trato entre la Mamora y Salé» de modo que, añadía, «se han fundado sobre ella [la autorización regia] las certificaciones que hice dar a algunos mercaderes para que la correspondencia de aquellas plazas se continuase [...] y que no tenía limitación». Es decir, el duque había puesto en marcha un comercio excepcional, no sabemos de qué volumen, pero presumiblemente estable, entre Mamora, Salé y Andalucía, dentro de un panorama general de intercambios tolerados en aras del pragmatismo (Martín Corrales, 2005, pp. 145-146; Martín Corrales, 2008).

La única limitación que en 1625 había impuesto el monarca al proyecto del duque era evitar que por ese camino entrasen en Castilla «mercaderías de rebeldes» - es decir, holandesas - adquiridas en Salé, cuestión a la que el duque afirmaba haber respondido ya el 21 de febrero de ese mismo año ${ }^{27}$. Esta limitación no era especulativa, desde luego, ya que por entonces los intercambios entre las Provincias Unidas y Salé se encontraban en uno de sus momentos más intensos, lo que permitió a los moriscos proveerse de armas, bastimentos navales y manufacturas holandesas

26 AGFCMS, leg. 2.414, carta de Felipe IV de 16 de agosto de 1625.

27 AGFCMS, leg. 2.414, Medina Sidonia a Pedro Coloma, sin fecha, de agosto o septiembre de 1631. 
(Maziane, 2002, p. 261). Solo podemos hacer conjeturas respecto a qué nutría el comercio auspiciado por Medina Sidonia, pero es claro que se desarrollaba bajo su control, con su licencia y con seguridad sin supervisión fiscal por parte del almojarifazgo de Berbería. Tampoco podemos tener seguridad de si las licencias ducales se usaban para algo más que para comerciar entre Mamora y Salé, aunque es probable que se utilizasen para negociar también con otras plazas de Berbería. Así parece indicarlo el interrogatorio sobre diversos asuntos de política interna marroquí que se realizó a un mercader francés que llegó a Sanlúcar en el verano de 1631. Dicho mercader declaró estar de regreso de Safi, adonde había ido a comprar trigo para traerlo a Sanlúcar, aunque su propósito se frustró porque el jerife de Marrakech había prohibido por sorpresa ese comercio ${ }^{28}$. Al año siguiente, cuando se encomendó a Medina Sidonia averiguar cierta contratación con Tetuán que un portugués había hecho con colaboración de la guarnición de Tarifa, el duque advirtió que aquello debía ser castigado, no por el hecho de comerciar con infieles, sino para evitar que aquel tráfico se realizase por lugares diferentes a los presidios atlánticos de Castilla ${ }^{29}$.

En parte porque, al igual que sucedía en Orán, aquellos tratos abrían múltiples posibilidades para las actividades ilícitas, todos estos manejos provocaron suspicacias y recelos entre algunos consejeros en Madrid, aunque no tanto en Felipe IV (Alonso Acero, 2017). A fines de 1631, meses después de que ciertos consejeros próximos al valido hubieran llamado la atención sobre aquél comercio entre Salé y Mamora, «una persona celosa» del servicio regio elevó un memorial que llegó a la consideración del monarca donde se analizaban los pros y contras del tráfico con Berbería, con una clara visión negativa de tal posibilidad. La principal causa que se alegaba para oponerse a ello era la falta de reciprocidad que existía en los intercambios, puesto que cuando el comercio estaba abierto se podía negociar desde cualquier puerto de España, mientras que el jerife de Marruecos abría solo unos puntos determinados según sus conveniencias (Bunes Ibarra, 2005, pp. 163-171).

Felipe IV remitió el memorial a Medina Sidonia solicitando también su opinión, a lo que el duque respondió en febrero de 1632 erigiéndose en portavoz de las autoridades del atlántico magrebí, puesto que afirmaba haber consultado con Fernando Mascarenhas — gobernador de Tánger-y Pedro Barrionuevo — gobernador de Mamora-, además de con los gobernadores de Ceuta y Larache. Partiendo del reconocimiento implícito de que las mercaderías procedentes de África que llegaban a Andalucía se transportaban en barcos españoles o, al menos, no magrebíes, Medina Sidonia se mostraba partidario de mantener abierto el comercio de forma general por lo importante que era para la supervivencia de los presidios, ya que los derechos que devengaba se usaban para su propio socorro. Al mismo tiempo, Medi-

28 AGFCMS, leg. 2.414, declaración de "Richarte Beamont", 17 de agosto de 1631.

29 AGS, Guerra Antigua, leg. 1.051, 24 de marzo de 1632. 
na Sidonia argumentaba que, gracias a ese comercio de proximidad con los «moros de paz», se podían ahorrar costes comprando bastimentos «a precios acomodados», evitando además los riesgos de la navegación desde la península, como ya sucedía en Orán-Mazalquivir (Alonso Acero, 2000, p. 288). Por último, señalaba que el intercambio comercial permitía recibir información de lo que sucedía en el interior de Berbería. Con estas premisas, el duque respondió al memorial criticando la generalidad con la que planteaba una cuestión que afectaba a plazas tan distantes unas de otras y con casuísticas tan diversas ${ }^{30}$.

Desconocemos si el rey o el consejo se pronunciaron sobre el tema, pero el memorial y la respuesta del duque revelan que el debate sobre las plazas africanas tenía una clara vertiente mercantil. Más aún, demuestra que donde se entrecruzaban comercio y finanzas es precisamente donde todo el sistema se enfrentaba de forma más directa a sus propias contradicciones. Para Medina Sidonia, si bien el balance de costes y beneficios era más ambiguo de lo que a primera vista pudiera parecer, el paradójico resultado de todo ello era que cuanto más éxito tenía el duque en la ampliación de su margen de decisión en la frontera africana, mayor era el esfuerzo económico que le suponía dicha labor por dejación de la corte.

\section{Fernando Novela: un asentista en tiempo de turbulencias financieras}

Fueran cuales fuesen los rendimientos fiscales del comercio abierto en los presidios, el sistema seguía siendo deficitario, de forma que Medina Sidonia continuaba cubriendo lagunas de financiación y ocupando áreas de decisión no atendidas desde la corte. Para poner remedio a ambas cosas, en algún momento de 1626 se aprobó, por primera vez que tengamos constancia, una consignación específica para los presidios de Larache y Mamora, al tiempo que se firmaba un primer asiento con cargo a dicha partida para su provisión, contrato en cuya formalización parece que el duque apenas tuvo intervención. A modo de contraste, recordemos lo que venía sucediendo en Orán-Mazalquivir, presidio en el que, cuando el cargo sobre las «Tres Gracias» se agotó, casi de inmediato se sustituyó, pese a las fricciones entre Guerra y Hacienda, por los «millones» u otras rentas regias (Alonso Acero, 2000, pp. 322-331). En el caso de nuestros presidios, cuando los retrasos en la libranza de las consignaciones volvieron a sucederse en grandes cantidades, Medina Sidonia convocó una junta con dichos asentistas para abordar los problemas más urgentes. Como resultado, se acordó solicitar a la corte 30.000 ducados para restaurar a los propios asentista

$30 \quad$ AGFCMS, leg, 2.415, carta de Medina Sidonia a Felipe IV por mano del secretario Ezcaray, 22 de febrero de 1632 . 
en su crédito en un momento — según argumentaron — de especial peligro para los presidios. Ahora bien, aunque se logró el envío de 20.000 ducados, el marqués de Montesclaros — presidente de Hacienda — restó importancia a la amenaza sobre los $\operatorname{presidios}^{31}$.

Frente al cuestionamiento de su gestión que suponía introducir esta duda, la reacción de Medina Sidonia fue tratar de apuntalar su implicación en los asuntos africanos ampliando su margen de acción mediante un protocolo de actuación completo en caso de emergencia que le hubiera dado un amplísimo margen de maniobra, al poner bajo su mando directo a las principales autoridades de la Baja Andalucía, incluido el asistente de Sevilla o el Consulado de Indias (Salas Almela, 2008, pp. 277-278). Aunque el proyecto no fue aprobado, el duque continuó forzando sus márgenes de acción en la medida en que era su propia casa señorial la que estaba asegurando, en última instancia, toda aquella frontera. Por ejemplo, en 1628 el duque tomó 12.000 ducados de manos del depositario de las almadrabas reales de Santipetri para socorrer a ciertos soldados de infantería que se enviaron a Cádiz para su defensa, cosa que aprobó el consejo de Guerra por la urgencia de la situación, aunque enfatizando que no debía repetirse en el futuro ${ }^{32}$. Como se ve, la respuesta de la corte a las acciones del duque no fue uniforme, puesto que al tiempo que se le agradecían y reconocían sus esfuerzos, se trataba de acotar su manejo de la hacienda del rey. En este sentido, Medina Sidonia solía contar con el apoyo sólido del consejo de Guerra y, algo menos decidido, del de Estado, pero, en cambio, entre los gestores de las finanzas reales la respuesta solía oscilar entre la suspicacia y el rechazo a muchas de sus iniciativas. Felipe IV, por su parte, se mostraba más próximo a la actitud favorable de Guerra, convencido de la necesidad de evitar la pérdida de presidios e incluso partidario de la utilidad de extender sus posesiones en el Magreb.

La situación, en todo caso, era desesperada a comienzos de 1628. En febrero el consejo de Guerra vio un memorial firmado por un segundo grupo de asentistas - que había reemplazado a los de 1626 - cuyo contrato para la provisión de los presidios databa de apenas unos meses atrás. En su escrito, los firmantes denunciaban que las deudas acumuladas alcanzaban ya la cifra de 163.000 ducados, lamentando al mismo tiempo que, habiendo tratado con los contadores mayores, estos no les ofrecían solución con el pretexto de la falta de fondos. Así las cosas, apelaban a la conciencia del rey para que tuviese en consideración el sufrimiento de los soldados y el riesgo de perder ambos presidios ${ }^{33}$. Estos peligros se hicieron tangibles en otoño, cuando Mamora sufrió un sitio que no terminó con la caída de la plaza

31 AGFCMS, leg. 2.413, 23 y 27 de marzo, 24 de abril, 9 de mayo y 6 de julio de 1627; AGS, Estado, leg. 2.646, d. 21 y 24,27 de abril de 1627.

32 AGS, Guerra Antigua, leg. 969, consulta de 13 de noviembre de 1628.

33 AGS, Guerra Antigua, leg. 969, consulta de 21 de febrero de 1628. 
gracias al gran valor de los soldados, según el consejo de Guerra ${ }^{34}$. Seguramente este peligro inminente contribuyó a que se diese por liquidado el asiento vigente para sustituirlo por uno nuevo mucho más del gusto de Medina Sidonia. En efecto, por entonces se produjo la irrupción, como proveedor de Larache y Mamora, de Fernando de Novela. Terrateniente y mercader de productos agropecuarios, Novela era miembro de una antigua parentela de servidores de los duques oriundos de la ciudad de Medina Sidonia, aunque con importantes lazos familiares en Sanlúcar. El propio flamante asentista había sido tesorero del VII duque don Alonso y, ocasionalmente, también del VIII, permaneciendo muy vinculado a las finanzas de la

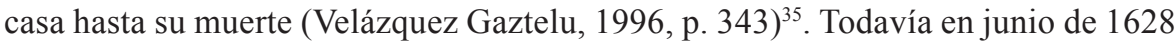
el duque dirigió un documento a Novela en su calidad de «tesorero general de mi casa y estado» ${ }^{36}$. Sea como fuere, una de las razones que hacía atractivo para los comerciantes la firma de estos asientos era el disfrute de las franquezas que implicaba asumir contratos de aprovisionamiento (Sanz Ayán, 2004, pp. 65-77). Sin embargo, no era ésta desde luego la causa principal que impulsó a Novela a convertirse en «partícipe y administrador» de los bastimentos y a correr — a la vista de los antecedentes - importantes riesgos con su propia hacienda. El cálculo general de sus posibilidades descansaba más bien en los variados negocios que se le ofrecían al gozar del pleno apoyo del duque, puesto que ello le permitiría beneficiarse de los intercambios mercantiles con las plazas africanas, al mismo tiempo que quedaba en manos de Novela decidir de dónde iban a proceder las provisiones, cuestión que, dada la condición de terratenientes, tanto del duque como de su criado, abría amplias posibilidades de colocar su excedente agrario. El punto débil, de nuevo, radicaba en la dependencia de todo el negocio de la puntualidad en la aportación de fondos por parte del consejo de Hacienda.

La historia de este arrendamiento hasta el experimento de la sal de 1631 nos es básicamente conocida. Nos consta así que cuando los problemas generados desde el comienzo por los retrasos en las libranzas parecieron solucionarse con la asignación de parte de las rentas de millones de Cádiz, Jerez y El Puerto de Santa María para la provisión de los presidios, la implantación del tributo único de la sal en enero de 1631 dejó en papel mojado una solución que parecía colmar las aspiraciones de Medina Sidonia (Gelabert, 2001, pp. 17-66; Salas Almela, 2008, pp. 279-283). Previamente, entre la firma del contrato y diciembre de 1630 se habían puesto de manifiesto algunas tensiones en las que conviene que reparemos.

AGS, Guerra Antigua, leg. 969, consulta de 28 de octubre de 1628 .

En la década de 1530 Diego de Novela había casado con una señora de Sanlúcar; en 1585 nos consta que su hijo, Juan de Novela, era regidor y vecino de Medina Sidonia. AGFCMS, leg. 780, auto judicial de 24 de noviembre de 1585 .

AGFCMS, leg. 3.043, orden del duque a Novela de 4 de junio de 1627. 
En primer lugar, es importante subrayar los esfuerzos que realizó el duque por aprovechar su ascendiente sobre Novela con el fin de controlar todos los aspectos relativos al sostenimiento de los presidios, como demuestra que intentase de nuevo sacudirse la supervisión de la veeduría de bastimentos. El agrio episodio de confrontación del duque con Luis Sáenz de Oyanguren y Juan de Otáñez en 1630 - cuando el duque obvió este cauce para el envío urgente de bastimentos comprados a su costa - es revelador de las contradicciones que se seguían produciendo cuando el sistema de supervisión, ideado para vigilar el empleo de los caudales del rey, era financiado por una hacienda diferente y que aspiraba a resarcirse de algún modo.

En segundo lugar, no menos significativo resulta que la aparente solución que significaba la consignación del asiento sobre rentas ciertas la aprobase el presidente del consejo de Hacienda muy pocas semanas antes de que se suspendiese el impuesto de los millones para sustituirlo por el de la sal. Nos resulta imposible penetrar en la intención de Castrofuerte en aquellas semanas. Por un lado, cabría pensar que la concesión al duque y a Novela de la ansiada consignación, dado que estaba abocada al fracaso debido al experimento de la sal, era una forma de situar a Medina Sidonia en la oposición más radical contra el experimento de la sal, por este motivo entre otros muchos. No podemos olvidar que también el propio consejo de Hacienda militaba en esa oposición a la reforma. Por otro lado, obviamente, tampoco podemos descartar que el presidente pudiera estar simplemente aparentando normalidad para ocultar los planes de reforma. En todo caso, lo que resulta de todo punto impensable es que en diciembre de 1630 el presidente de Hacienda no tuviera noticia de los inminentes y radicales planes de transformación fiscal que se iban a poner en marcha en pocos días (Gelabert, 2001, p. 21).

De uno u otro modo, el fracaso del experimento de la sal afectó de forma muy notable a Larache y Mamora, que quedaron durante meses de nuevo en una posición de necesidad extrema al no haber fondos con los que cubrir el asiento firmado con Novela. En tales circunstancias, en febrero de 1631 parte de la dotación del presidio de Larache hizo una salida para buscar bastimentos en el contorno, siendo objeto de una emboscada. El resultado fue la captura de 70 soldados, lo que dejó en situación límite a ambos presidios (Bacaicoa Arnáiz, 1956). Antonio Chumacero, por entonces administrador de la nueva renta de la sal en Andalucía, recibió órdenes del rey para la provisión de fondos, pero de inmediato expresó al duque la imposibilidad de hallar dinero alguno procedente de la nueva tasa al menos hasta junio ${ }^{37}$. Así las cosas, con un Fernando Novela en quiebra técnica, solo cabían dos opciones perfectamente compatibles entre sí: por una parte, que fuese el duque quien de nuevo supliese las carencias de la real hacienda; por otra parte, al mismo tiempo el duque consideró 
oportuno pasar a negociar con el máximo responsable de la ejecución de la política de la monarquía: el conde-duque de Olivares.

En primer lugar, empujado por la situación, pero también como fórmula para reforzar su posición, Medina Sidonia redobló su compromiso cuando en marzo de 1631 logró de nuevo reunir a su costa una importante carga de bastimentos y hacerla llegar a Larache y Mamora junto con los refuerzos de hombres. Este hecho le permitió, ya en abril, adoptar un tono más duro exigiendo respuesta. En carta dirigida al rey por la vía de Guerra, el duque narró a Felipe IV cómo pudo hacer llegar a Larache y Mamora un contingente de,

17 bajeles de bastimentos, pertrechos, armas y municiones [...] que previne con la gente que pasó a la Mamora [...], con que parece que de diferentes milagros se ha compuesto este socorro, comenzando desde el hacerlo yo tan a tiempo como sin ayuda y sin caudal, pues de todo punto se ha servido Vuestra Majestad de permitir que ni aún para sustento tan forzoso se provea de dineros.

La amargura de su queja procedía, como no ocultaba el duque, de haber tenido que proveerlo todo a su costa, no tanto por falta de recursos regios como por falta de resolución. Tras advertir los escrúpulos que le provocaba estar arruinando a otros, el duque glosaba el tópico de la inalienabilidad del alma al recordar que «teniendo ofrecida y puesta la vida y el caudal a los pies de Vuestra Majestad, si mi conciencia peligra excusaré todo lo que fuere contra ella, por grandes que sean los aprietos» ${ }^{38}$. Al mismo tiempo, el duque se dirigió unos días después al rey a través del consejo de Hacienda, exponiendo que si no hubiera sido por su acción las plazas se habrían perdido, de tal modo que «hoy se sustentan con lo que de mi hacienda y de otras me he valido», incluso «llegando a usar de algunas violencias». Calculando que había en los presidios bastimentos para resistir solo hasta junio y señalando que su crédito se hallaba agotado, el duque se sentía obligado a llamar la atención de nuevo sobre los inminentes peligros para evitar que la pérdida de las plazas, que estimaba cuestión de tiempo, se achacase a su falta de atención ${ }^{39}$. Posiblemente por indicación de Medina Sidonia, justo por entonces los gobernadores de Mamora y Larache elaboraron sendos informes detallando las provisiones y bastimentos de los que disponían, haciendo un cálculo del poco tiempo que tardarían en agotarse ${ }^{40}$.

En segundo lugar, no es casual que justo entonces Medina Sidonia apelase a su pariente en un asunto en el que antes no había solido requerir su mediación, pese a que Olivares era un contacto habitual del duque en sus negociaciones con la corte

38 AGFCMS, leg. 2.415, carta de Medina Sidonia a Felipe IV, 15 de abril de 1632.

39 AGFCMS, leg. 2.415, 18 de abril de 1632.

40 AGS, Estado, 2.650, n. 121 y 122, relaciones de bastimentos fechas a 22 y 27 de abril de 1632, respectivamente. 
(Salas Almela, 2006). Además, hay que tener en cuenta que también por entonces el valido estaba empeñado en un plan de reforma del sistema de mantenimiento de los presidios de España por virtud del cual pretendía establecer una partida fija, evitando que unos estuvieran bien provistos y otros en la indigencia, al tiempo que aspiraba a convertirlos en viveros de tropas castellanas para los ejércitos de Felipe IV (Elliott y de la Peña, 1981, tomo II, pp. 106-107; Thompson, 1991, p. 459). Sea como fuere, a principios de abril Medina Sidonia escribió al valido para representarle el desolador panorama de los presidios bajo su mando, cuya caída implicaría una gran pérdida de reputación para Felipe IV y el propio Olivares. El duque se excusaba de importunarle con ello recordando que de ordinario no solo no le molestaba, sino que muy al contrario le aliviaba de tal carga en cuanto estaba en su mano ${ }^{41}$. Olivares reconoció los grandes servicios que continuamente hacía el duque a la monarquía, anunciando que iba a disponer el envío de 30.000 ducados de los que se debían de lo consignado en la sal, partida que, según nos consta, iba a resultar bastante problemático hacer efectiva. Asimismo, Olivares aprobaba el envío urgente de refuerzos como proponía el duque. Sin embargo, en lo que se mostraba muy suspicaz era en la cuestión de las salidas de los soldados de los presidios, puesto que daba por hecho que no eran fruto de la necesidad, sino del deseo de «hurtar» en las poblaciones vecinas ${ }^{42}$.

Al reconocimiento de los desvelos del duque se sumaron entre otros el marqués de Castañeda, presidente de Guerra, que se explayó en sus muestras de apoyo, subrayando ciertos argumentos muy del gusto del duque. Afirmaba que el rey había remitido dineros, bastimentos y hombres directamente al duque «porque cosas tan grandes no pueden ni deben pasar por menores manos ni por ánimos menos generosos que el que Vuestra Excelencia tiene, grande señor». Para disipar cualquier duda del apoyo que Guerra prestaba a las reclamaciones del duque, afirmaba que «no tiene ya palabras [el consejo] con qué representar a Su Majestad la calidad de las obras de Vuestra Excelencia y que si Su Majestad se conforma y conformare con mi voto, que se había de hallar Vuestra Excelencia muy satisfecho» ${ }^{43}$.

Medina Sidonia respondió a Olivares mostrándose dispuesto a seguir asumiendo todos los sacrificios necesarios, pero señalaba su temor respecto al inmediato futuro por «faltarme a mí el camino de hacerlas [las finezas] como hasta ahora». Añadía, para reforzar la idea de sus escasos medios, que «ningún vasallo del rey puede lo que no le es posible a Su Majestad; y el obrar desde aquí faltándonos este [apoyo] todo es enviar puntos y ocasiones de quejas y riesgos a las plazas, de que Dios las libre ${ }^{44}$. De este modo, Medina Sidonia buscaba indirectamente disipar las suspicacias respecto

41 AGFCMS, leg. 2.414, 6 de abril de 1631.

42 AGFCMS, leg. 2.414, 28 de abril de 1631.

43 AGFCMS, leg. 2.414, 6 de mayo de 1631.

44 AFCMS, leg. 2.414, 11 de mayo de 1631. 
a los retornos que sus manejos con los presidios pudieran reportarle, puesto que el problema era de tal magnitud que las propias plazas estaban en riesgo de caer. Es decir, el duque planteaba que si para él hubiera sido beneficioso el sistema tal como estaba, sus finanzas no estarían en riesgo de perderse. Para lo más inmediato, el secretario Ruiz de Ezcaray comunicó al duque que el rey había ordenado expresamente a Sevilla y Jerez que remitiesen sin dilación hombres de sus milicias como refuerzo para Larache y Mamora. Sin embargo, ya en junio Medina Sidonia escribió de nuevo al conde-duque lamentando una vez más que el exceso de confianza en su capacidad logística «ha de ser la pérdida de ellas [las plazas]», denunciando que el rey las había dejado «de abastecer tantas veces y tanto tiempo» ${ }^{45}$.

Olivares respondió aumentando su presión al duque al señalar que temía que otros aristócratas pudieran adelantarle en finezas al rey, lo que a su vez provocó una respuesta del duque en la que no solo ensalzó sus propios servicios, pese a las dificultades financieras de su casa, sino que además enfatizó un interesante argumento de conciencia. Así, al recordar cómo había recurrido hasta entonces a su propia fuerza, «sin haber valídome de las ajenas [de sus deudos], con destrucción de las personas que por haberme de obedecer han acudido a estos socorros, debiéndose a ellas y a otras muchas sus haciendas, corriendo mi crédito y mi conciencia el riesgo que ellos en tanto que no se satisface». De entre aquellos a los que el duque estaba destruyendo por servirle, obviamente Novela era el principal. A Medina Sidonia ya no solo le preocupaban sus propias rentas, sino haber forzado a sus criados al desastre económico. Más aún, todo ello le estaba conduciendo a una pérdida de crédito en términos sociales y financieros incluso entre las autoridades de los presidios, que ya no mostraban tanto gratitud hacia él como quejas por no recibir los socorros acostumbrados. Para rematar, el duque situaba al valido ante un problema también de conciencia religiosa, señalando que era obligación de la hacienda del rey proveer el socorro, puesto que los soldados «perecen por falta de él y niegan la fe» ${ }^{46}$.

Aunque no estuviesen dando resultados tangibles en forma de dineros seguros y provisiones constantes, lo cierto es que la combinación de las amenazas y las acciones de Medina Sidonia tuvieron el efecto de extender en la corte del rey católico la idea de que era necesario poner remedio en aquella frontera, sumándose a las reclamaciones del consejo de Guerra el de Estado. El 20 de mayo se reunió este último organismo con cartas de Medina Sidonia y del gobernador de Mamora. El resumen introductorio para la consulta recogió expresamente la idea de que aunque «el duque emplee allí toda su hacienda, no puede acudir a lo necesario». La conclusión, pues, no podía ser otra que la de urgir una vez más el envío del

45 AGFCMS, leg. 2.414, cédula de Felipe IV a Medina Sidonia por el consejo de Guerra, 6 de marzo y carta del duque a Olivares de 29 de junio, ambas de 1631. 
dinero necesario siquiera para ese verano y buscar medios para asegurarlo en lo venidero ${ }^{47}$. Pese a ello, todavía a fines de mayo el duque desesperaba ante un nuevo incumplimiento de los plazos del renovado asiento para el sostenimiento de los presidios que había firmado Novela, insistiendo en que sus propias fuerzas ya no daban para suplir todas las carencias ${ }^{48}$. Por entonces Medina Sidonia centraba sus críticas en la inoperancia del consejo de Hacienda, incapaz de ejecutar lo que Felipe IV le ordenaba una y otra vez. Así, por ejemplo, si bien el rey había ordenado a mediados de junio que se diese satisfacción a la consignación de Mamora, Medina Sidonia denunció semanas después que tampoco aquella taxativa orden estaba teniendo consecuencias prácticas ${ }^{49}$.

En efecto, en primavera de 1631 se había vuelto a firmar un nuevo asiento con Fernando Novela, en buena medida con la intención de permitirle resarcirse de sus pérdidas, pero también para dar continuidad al aprovisionamiento en un momento especialmente delicado. Igualmente, se le aprobaron las cuentas pasadas, reconociendo las enormes deudas contraídas. Pese a todo, el dinero seguía sin llegar. En agosto se reunió el consejo de Guerra con una serie de consultas previas de la junta de presidios y del consejo de Hacienda para tratar de la angustiosa situación de Larache y Mamora ${ }^{50}$. La propuesta que presentó por entonces Hacienda consistía en ordenar que,

se valga el duque por vía de empréstito del último donativo de Cádiz, Jerez de la Frontera, Sanlúcar y El Puerto de Santa María [de] hasta ocho o diez mil ducados, a volverlos del asiento de Novela y también de los bastimentos que tiene la armada o galeras, con calidad de restituirlo de lo que ha de proveer este asentista.

Esto prueba que en la interpretación de los gestores de las finanzas de Felipe IV el problema no era en sí mismo el asiento firmado con Novela, sino las dificultades que se estaban encontrando para hacer efectivas las partidas, lo que presuponía que el problema no era estructural sino temporal. Por su parte, el consejo de Guerra se limitó a señalar que la provisión de una partida de 50.000 ducados que se debían a cuenta de lo invertido en las plazas no podía quedar en manos de la Junta de Presidios porque este organismo no tenía autoridad sobre las libranzas, de modo que trasladaba así mismo el asunto a Hacienda.

47 AGS, Estado, leg. 2.650, n. 131, consulta del consejo de Estado de 20 de mayo de 1632.

48 AGFCMS, leg. 2.415, cartas de Medina Sidonia a Felipe IV y Ruiz de Ezcaray, de 23 y 30 de mayo de 1632.

49 AGFCMS, leg. 2.415, carta de Felipe IV 15 de junio y respuesta de Medina Sidonia al rey de 27 de junio de 1632 .

50 Esta consulta prueba que antes de 1634 ya existía una «junta de presidios», como mínimo antecedente directo de la que cita Sanz Ayán (2015, ebook pos. 3.431-5.725). 
El rey aprobó que se recurriese al donativo, pero solo hasta 3.000 ducados y solo de los lugares más próximos a Cádiz y Sanlúcar ${ }^{51}$. Ya en octubre, el consejo de Guerra se reunió para discutir una súplica remitida por Novela en la que entre otras cosas afirmaba que a esas alturas los dueños de los bastimentos se negaban a entregarle nada por los múltiples retrasos sufridos. Así las cosas, Novela amenazaba con desistir del asiento amparado en la pura y simple imposibilidad creada por los incumplimientos de la Real Hacienda. Guerra se limitó a apoyar las demandas de Novela y dar curso a la consulta al rey, mientras que la respuesta de Felipe IV a comienzos de noviembre consistió en ordenar a Hacienda dar satisfacción al asentista sobre los millones viejos del partido de Sevilla ${ }^{52}$. En diciembre el duque hizo balance de la frustrante respuesta que habían tenido todas sus demandas de aquel año. Recordaba que, más allá de palabras «siempre con esperanzas» de una solución estable, solo se habían librado dos partidas que apenas sumaban 24.000 ducados, cifra a la que el duque oponía la cantidad teórica de 140.000 anuales firmados en el asiento. Así, el ejercicio contable se cerraba como comenzó, con el duque cubriendo lo que podía de las necesidades más básicas y arrastrando a los asentistas a un callejón sin salida. Apelando de nuevo a la conciencia regia, afirmaba que lo peor era la situación de los soldados, amenazados en sus vidas y almas, tanto si caían cautivos como si renegaban empujados por la desesperación y el hambre ${ }^{53}$.

Sin embargo, unos meses después el ambicioso plan sobre los presidios de España auspiciado por Olivares y pensado ante todo para reforzar la frontera con Francia, abarcó también la financiación de todos los presidios. En consecuencia, en 1632 se firmó un asiento con Octavio Centurión, marqués de Monasterio, que debía cubrir los años 1633 a 1638, según el cual, a cambio de garantizar provisiones por valor de unos 720.000 ducados anuales. El banquero recibiría no solo lo que tocaba a la Real Hacienda para dicho fin, sino también una parte de los millones cobrados en las ciudades y lugares a los que correspondía sostener presidios. Lo irónico del caso, según recogen Elliott y de la Peña, es que en 1633 el dinero previsto superó con mucho los gastos porque lo que faltaba por entonces eran soldados ${ }^{54}$.

51 AGS, Guerra y Marina, leg. 1.049, consulta de 13 de agosto y respuesta de 4 de septiembre de 1632.

52 AGS, Guerra y Marina, leg. 1.049, consulta del consejo de 7 de octubre y respuesta manuscrita del rey de 3 de noviembre de 1632 .

53 AGFCMS, leg. 2.415, Medina Sidonia a Felipe IV por mano de Ruiz de Ezcaray, 12 de diciembre de 1632 .

54 Existe una contradicción entre los datos que aportan Elliott y de la Peña y el que ofrece Sanz Ayán, puesto que los primeros fechan el primer asiento en 1632 y la segunda autora en 1634. Nuestra información confirma que el primer año de vigencia del asiento era 1633 (véase Elliott y de la Peña, 1981, tomo II, 107-109; Sanz Ayán, 2015, pos. 3.444-5.725). La participación de Centurión en la provisión de los presidios en AGS, Guerra Antigua, leg. 1.073, carta de Medina Sidonia de 20 de febrero de 1633. 
En lo que respecta a Larache y Mamora, el nuevo contrato no expulsaba a Novela, sino que éste quedó como proveedor específico de las fronteras bajo mando de Medina Sidonia. Como ha señalado Sanz Ayán, los comienzos del asiento de Centurión tuvieron serias dificultades, pero en todo caso supuso un paso fundamental en el proceso de normalización del control castellano sobre los presidios que nos ocupan. Por otro lado, pese a los excepcionales excedentes iniciales del nuevo asiento, lo adeudado a Novela siguió pesando mucho en las relaciones entre el duque y la corte porque todas las partidas que se señalaban para su cobro resultaban inciertas ${ }^{55}$. Para compensarle, también le fueron entregados varios oficios - como el de medidor del trigo- y la gestión de algunas rentas — como el estanco del aguardiente-, aunque hacerlos efectivos generó nuevos problemas ${ }^{56}$. Por su parte, el asiento con Centurión situaba a Medina Sidonia en una posición muy ajustada a sus esperanzas, puesto que las libranzas se hacían a favor de Novela - como proveedor - para ser invertidas por orden del duque, lo que le otorgaba un amplio control de la cadena de mando y suministro de los presidios ${ }^{57}$.

No obstante, en los tres años que restaban de vida al VIII duque ni mucho menos desaparecieron los problemas, puesto que el banquero no siempre cumplió con las consignaciones ya que también Centurión se topó con el inconveniente de que las rentas señaladas resultaron muchas veces inciertas. Para el caso que nos ocupa, a fines de 1633 se comenzó a barajar como solución sustituir los millones de algunas localidades de la costa de la Baja Andalucía por los derechos que se cobraban sobre el pescado, renta de reciente implantación cuya finalidad era financiar la fortificación de Cádiz $^{58}$. Medina Sidonia presionó en la corte por todos los medios a su alcance - sobre todo su agente en Madrid, su hijo y heredero y su hermano don Alonso, Patriarca de las Indias y limosnero mayor del rey — para que se aprobase esta solución ${ }^{59}$. Para entonces, Novela ya solo buscaba la forma de desvincularse de los asientos sin tener que dar por perdido lo que se le adeudaba, asunto en el que contó con el apoyo del consejo de Guerra no tanto por escrúpulos de conciencia sino porque «no cumpliéndose con él, no habrá quien quiera entrar en el nuevo asiento de aquellas plazas $\rangle^{60}$. Así las cosas, en agosto de 1634, dado que Centurión todavía no había podido remitir

55 AGS, Guerra Antigua, leg. 1.049, 7 de octubre de 1632 y leg. 1.073, 7 y 19 de enero de 1633.

56 AGS, Guerra Antigua, leg. 1.073, 17 de octubre de 1633.

57 AGS, Guerra Antigua, leg. 1.073, 20 de febrero y 7 de marzo de 1633.

58 Mencionaba el duque la materia en carta a su agente de 4 de septiembre de 1633. AFCMS, leg. 3.063 .

59 AFCMS, leg. 3.063, carta de 20 de noviembre de 1633

60 Novela escribió un memorial al consejo de Guerra narrando cómo ni el oficio de medidor de trigo —nunca puesto en servicio en muchas localidades-, ni 32.000 ducados que se había ordenado entregarle a Manuel Pantoja procedentes de los millones de Sevilla, ni tampoco el donativo ni el asiento de Monasterio habían resultado ciertos. AGS, Guerra Antigua, leg. 1.095, 20 de marzo de 1634. 
el dinero que se le había ordenado de ese año para Larache y Mamora, Medina Sidonia volvió a cubrir las carencias del sistema con sus propios medios.

En definitiva, pese a que la financiación del sostenimiento de Larache y Mamora estaba alcanzando una suerte de estabilidad al menos teórica, visto en perspectiva el problema de fondo fue que las soluciones llegaron tarde. Así, cuando un cuarto de siglo después de la incorporación de los presidios a la monarquía se empezaron a arbitrar esas soluciones válidas, su situación financiera estaba ya en tan avanzado estado de deterioro que resultaron poco efectivas. Algo de lo que tampoco escapó, pese a todo, el asiento de Centurión. Además, en 1632 las urgencias de Felipe IV se centraban en reclamar nuevos fondos para la guerra en Alemania. En el contexto de las cortes de Castilla de ese año, el rey también solicitó ayuda a los aristócratas tanto por medio del reclutamiento de coronelías como en forma de ayuda financiera. En este último sentido, según el embajador inglés sir Arthur Hopton, a Medina Sidonia le correspondieron «mucho más» de 100.000 ducados (Elliott, 1991, p. 433; Gelabert, 1997, pp. 90-103). Los muchos servicios previos permitieron a Medina Sidonia quedar exonerado de la coronelía, mientras que su servicio financiero se utilizó para saldar, al menos parcialmente, las cuentas de varios de sus anticipos previos. No obstante, el conde de Niebla — hijo y heredero del duque - sí que hubo de financiar una coronelía ${ }^{61}$.

Unos años después se impuso a la nobleza el servicio de lanzas, el cual, en el caso de Medina Sidonia - por entonces ya el IX duque — se vinculó al mantenimiento de los presidios bajo su mando. De este modo, en adelante Centurión se limitaría a otorgar cartas de pago de lo que don Gaspar Alonso invirtiera en los presidios ${ }^{62}$. Una situación que implicaba que el tradicional esfuerzo financiero de los duques se canalizase de un modo institucional que, de nuevo, permitía a Medina Sidonia que su servicio financiero al rey quedase bajo su propio control. Con todo, tampoco esta solución resultó estable porque su puesta en marcha generó nuevos problemas, de tal forma que tras la conjura del IX duque de Medina Sidonia en 1641 los experimentos continuaron (Guastavino Gallent, 1956).

\section{Conclusiones}

Con esto en mente, no parece que nuestro caso de estudio se ajuste del todo al modelo que planteó Thompson para el conjunto de la monarquía, según el cual el esfuerzo económico de la nobleza fue una forma de gravar indirectamente al estamento.

61 AGS, Guerra Antigua, leg. 1.051, 27 de septiembre y 31 de octubre de 1631, (véase también Salas Almela, 2002, pp. 131-132).

62 AGFCMS, leg. 993, «Carta de pago» fechada el 8 de agosto de 1637 respecto a lo aportado por el duque el año anterior. 
El caso de Larache y Mamora fue más bien resultado de la combinación de fuertes dosis de imprevisión y un contexto económico general en claro deterioro (Thompson, 1981, p. 193). La decisión de Felipe III y Lerma de ampliar las posesiones africanas de la Monarquía Hispánica incorporando Larache y tomando Mamora no estuvo acompañada de un plan específico para su aprovisionamiento. Lerma dio por supuesto que, dado que iban a pertenecer a Castilla, las nuevas adquisiciones se entendían como extensiones del sistema de defensa de la Baja Andalucía, lo que implicaba de forma más o menos consciente tres cuestiones fundamentales: en primer lugar, que la procedencia de tropas y refuerzos se vinculaba al amplio espacio costero de Sevilla; en segundo lugar, que los presidios se iban a insertar en el sistema de control y fiscalización de bastimentos de presidios de la Baja Andalucía; y, por último, que la autoridad que iba a asumir la responsabilidad sobre las dos plazas africanas era la del capitán general de la costa andaluza, el duque de Medina Sidonia.

Al igual que ocurría con la financiación, en este aspecto los casos de Larache y Mamora se diferencian de Orán-Mazalquivir, presidio que ejerció a través de sus gobernadores de intermediario entre la monarquía y los poderes magrebíes de la zona (Alonso Acero, 2000, p. 446). En el atlántico marroquí, en cambio, ese papel fue asumido plenamente por los Medina Sidonia. Pese a esta particularidad, hasta aquí el sistema no tenía por qué haber generado mayores problemas. Sin embargo, la falta de una financiación suficiente que padecía todo el sistema de presidios castellanos hizo que la ampliación de las necesidades y gastos generada por la incorporación de dos nuevas plazas no se pudiese asumir en las cuentas ordinarias.

Las ingentes riquezas de la casa de Medina Sidonia fueron el recurso de urgencia que cubrió carencias en los momentos de mayor peligro, tanto por cuestiones de prestigio señorial — el deseo de los duques de no ver dañado su crédito social si las plazas caían en manos del enemigo estando bajo su amparo-, como por los múltiples intereses que esta casa señorial tenía en toda la región marítima del lado atlántico del Estrecho de Gibraltar. Al mismo tiempo, este estado de cosas permitió al VIII duque encontrar vías por las que compensar parcialmente sus gastos, por ejemplo, fomentando el comercio con los presidios o situando sus excedentes agrícolas en el suministro de las plazas, si bien el cobro a posteriori fuese siempre azaroso. Aunque nunca lo citase expresamente, al menos que nosotros sepamos, da la impresión de que el modelo a imitar que don Manuel Alonso tuvo siempre en mente fue precisamente el de Orán-Mazalquivir, en el que la propia casa señorial había participado esporádicamente como contratista en 1606 (Alonso Acero, 2000, pp. 388-398; Alonso Acero, 2007, p. 756). Desde otro punto de vista, por lo que respecta a su cargo militar, pesó más lo económico que lo clientelar en la forma de rentabilizar el servicio que practicaron los Medina Sidonia si lo comparamos con el caso de los Mendoza y la capitanía general de Granada en el siglo XVI (Jiménez Estrella, 2004). Sea como 
fuere, pese a los medios arbitrados por los duques para amortiguar el peso sobre sus finanzas, ello no quiere decir que Medina Sidonia buscase conscientemente perpetuar esta situación. Por el contrario, hemos podido ver cómo de forma activa pugnó por encontrar vías de financiación a cargo de la Real Hacienda que le relevasen de estas obligaciones.

El análisis de los vaivenes de esta situación ha puesto así mismo de relieve la notable paradoja de que, en la medida en que el gobierno de la Monarquía Hispánica dejaba en manos de Medina Sidonia la iniciativa estratégica y financiera, ciertamente el duque podía ampliar su margen de acción e interpretación de las órdenes emanadas de la corte, aunque al precio de suplir lagunas de numerario de la hacienda regia. Con mucho esfuerzo, el VIII duque de Medina Sidonia logró ensayar algunas soluciones que hubieran supuesto un equilibrio entre su deseo de controlar la provisión de los presidios y la salvaguarda de su fortuna personal, entre ellas el asiento de Fernando Novela. El fracaso de aquella solución por culpa del experimento de la sal al menos sirvió para que los consejos de Estado y Guerra apoyasen sin fisuras el proyecto mucho más amplio del asiento firmado con Octavio Centurión. El asiento de Novela, diseñado a la medida de las conveniencias del duque, abría mejores perspectivas que el del genovés, si bien al menos podría haber sido una solución satisfactoria para el duque. La realidad fue, sin embargo, que la guerra no dejó de extenderse y con ella la escasez cada vez mayor de dinero, siendo 1635 - el año de la declaración de Guerra de Francia - el punto crítico que sometió los recursos de la Monarquía Hispánica a una tensión hasta entonces desconocida.

Desde el punto de vista de las relaciones de dicha monarquía con el Magreb, el caso de los Medina Sidonia constituye un excelente ejemplo de mediatización de aquella política, si bien con características diversas al modelo descrito para el área Mediterránea (Planas, 2001). Así, aunque la integración de los presidios africanos de Larache y Mamora bajo el mando de su capitanía abrió posibilidades que abarcaban desde la consolidación de su prestigio como defensores de la patria —el entorno de Sevilla y sus intereses mercantiles-, hasta la potenciación de su propio puerto de Sanlúcar, los problemas que venimos describiendo convirtieron aquellas posibilidades en una trampa financiera. En los mentideros sevillanos se rumoreó que el VII duque dejó en 1615 a sus descendientes, entre otras muchísimas cosas, la asombrosa cifra de seis millones de ducados en moneda, una opulencia que contrasta enormemente con el tesoro exhausto que quedó en 1635 tras la muerte del VIII duque (Salas Almela, 2016).

Obviamente los presidios fueron solo una parte de una crisis financiera señorial que tenía otros factores - la propia guerra con Francia, la irregularidad en el comercio en general y en la Carrera de Indias en particular o la disminución de las capturas de atunes en sus almadrabas-, pero lo que es innegable es que en la experiencia 
cotidiana del ejercicio del poder de estos aristócratas, el balance financiero distaba mucho de ser satisfactorio, por mucha gratitud que el consejo de Guerra expresase de forma casi rutinaria. Lo peor para el IX duque, sin embargo, fue que cuando accedió al trono ducal no existía otra posibilidad que perseverar en aquél empeño, puesto que no cumplir con las obligaciones heredadas hubiera implicado un descrédito - personal, político, social y también económico- que ningún aristócrata estaba dispuesto a asumir.

\section{AGRADECIMIENTOS}

Este trabajo ha sido financiado gracias a la ayuda de los proyectos de investigación PID2019-109168GB-100 del Ministerio de Ciencia, Innovación y Universidades, y UMA18-FEDERJA-098 de la Junta de Andalucía. La edición de este trabajo ha sido posible gracias a la ayuda del Programa de Grupos de Potencial Crecemento concedida por la Consellería de Cultura, Educación e Universidade da Xunta de Galicia al GI-1921 de la USC (Referencia: GPC, ED 431B 2021/06). 


\section{Bibliografía}

Alcalá-Zamora, José (1976), «Iniciativa, desaciertos y posibilismo en la política española bajo Felipe III», Estudios del Departamento de Historia Moderna, Zaragoza, Universidad de Zaragoza, pp. 191-224.

Alfani, Guido y di Tullio, Matteo (2019), The Lion's Share. Inequality and the Rise of the Fiscal State in Preindustrial Europe, Cambridge, Cambridge University Press. <https://doi.org/10.1017/9781108568043>.

Alonso Acero, Beatriz (2000), Orán-Mazalquivir, 1589-1639. Una sociedad española en la frontera de Berbería, Madrid, CSIC.

Alonso Acero, Beatriz (2001), «Las ciudades norteafricanas de la Monarquía Hispánica de los siglos XVI y XVII», Torre de los Lujanes, 45, pp. 123-144.

Alonso Acero, Beatriz (2007), «Trenes de avituallamiento en las plazas españolas de Berbería”, en García Hernán, Enrique y Maffi, Davide (eds.), Guerra y sociedad en la Monarquía Hispánica. Política, estrategia y cultura en la Europa moderna (1500-1700), Madrid, Mapfre-CSIC, 2007, vol. 1, pp. 739-766.

Allen, Paul (2000), Felipe III y la Pax Hispánica, 1598-1621, Madrid, Alianza.

Bacaicoa Arnáiz, Dora (1956), «Emboscada en Larache el 7 de febrero de 1631», Tamuda, 4 (1), pp. 93-99.

Bueno Soto, Francisco Javier (2008), «Larache y La Mamora: dos fortificaciones españolas en tiempos de Felipe III», Aldaba, 34, pp. 51-96. <https://doi. org/10.5944/aldaba.34.2010.20519>.

Bunes Ibarra, Miguel Ángel de (1988), «La vida en los presidios del norte de África», en Actas del Coloquio Relaciones de la Península Ibérica y el Magreb (siglos XIII-XVI), Madrid, CSIC, pp. 561-590.

Bunes IbARra, Miguel Ángel de (2005), «Relaciones económicas entre la Monarquía Hispánica y el Islam en época de Cervantes», Revista de Historia Económica, 23, pp. 161-177. <https://doi.org/10.1017/S0212610900012271>.

Bunes IbARRA, Miguel Ángel de (2011), «La ocupación de Larache en la época de Felipe III: una historia norteafricana en el Archivo General de Simancas», en Marcos Martín, Alberto (coord.). Hacer historia desde Simancas: homenaje a José Luis Rodríguez de Diego, Valladolid, Junta de Castilla y León, pp. 171-186.

Colección de Documentos Inéditos para la Historia de España (1856), Madrid, Imprenta de la Viuda de Calero, tomo 28.

Díez, Benito (1928), «Ocupación española de Larache en 1610», Mauritania, VII y VIII, pp. 183-185 y pp. 209-212. 
Domínguez Ortiz, Antonio (1960), Política y hacienda de Felipe IV, Madrid, Pegaso.

Elliott, John H. (1991), El conde-duque de Olivares. El político en una época de decadencia, Barcelona, Crítica [edición original, 1986].

Elliott, John H. y de la PeÑA, Juan F. (1981), Memoriales y cartas del conde-duque de Olivares, Madrid, Alfaguara, 2 tomos.

Feros, Antonio (2002), El duque de Lerma. Realeza y privanza en la España de Felipe III, Madrid, Marcial Pons.

García-Arenal, Mercedes, Rodríguez Mediano, Fernando y El Hour, Rachid (eds., 2002), Cartas marruecas: documentos de Marruecos en los archivos españoles (siglos XVI-XVII), Madrid, CSIC.

García Figueras, Tomás (1958), «Larache durante la dominación española, (1610 1689)», Revista de Historia Militar, 3, pp. 9-29.

García Figueras, Tomás y Rodríguez Jouliá Saint-Cyr, Carlos (1973), Larache. Datos para su historia en el siglo XVII, Madrid, CSIC.

García García, Bernardo (1997), La Pax Hispánica. Política exterior del duque de Lerma, Leuven, Leuven University Press.

Gelabert, Juan E. (1997), La bolsa del rey. Rey, reino y fisco en Castilla (15981648), Barcelona, Crítica.

Gelabert, Juan E. (2001), Castilla convulsa (1631-1652), Madrid, Marcial Pons.

Guastavino Gallent, Guillermo (1956), «Una propuesta de aprovisionamiento de Larache y La Mamora en 1643», Tamuda, 4 (1), pp. 53-70.

Hershenzorn, Daniel (2018), The Captive Sea. Slavery, Communication and Commerce in Early Modern Spain and the Mediterranean, Philadelphia, Pensilvania University Press. <https://doi.org/10.9783/9780812295368>.

IsRAEL, Jonathan (1997), La República holandesa y el mundo hispánico (1606-1661), Madrid, Nerea, pp. 34-35, [edición original, Oxford, 1982].

Jiménez Estrella, Antonio (2004), «Los Mendoza y la proveeduría general de armadas y presidios norteafricanos: servicio nobiliario y función militar en el marco geopolítico mediterráneo», Revista de Historia Militar, 95, pp. 123-155.

Martín Corrales, Eloy (2005), «De cómo el comercio se impuso a la razzia en las relaciones hispano-musulmanas en tiempos del Quijote: hacia la normalización del comercio con el norte de África y el levante otomano a caballos de los siglos XVI y XVII», Revista de Historia Económica, 23, pp. 139-159. <https:// doi.org/10.1017/S021261090001226X>.

Martín Corrales, Eloy (2008), «Exportaciones españolas al Mediterráneo musulmán (siglos XVI-XVIII)», en Martínez Torres, José Antonio (coord.), Circula- 
ción de personas e intercambios comerciales en el Mediterráneo y en el Atlántico (siglos XVI, XVII y XVIII), Madrid, CSIC, pp. 191-214.

Maziane, Leïla (2002), «Entre Salé et les Provinces-Unies au XVIIe siècle, une complicitè en couleur», en Crespo Solana, Ana y Herrero Sánchez, Manuel (coords.), España y las 17 Provincias Unidas de los Países Bajos, Córdoba, Universidad de Córdoba, tomo 1, pp. 255-267.

Planas, Natividad (2001), «La frontière franchissable: normes et practiques dans les échanges entre le royaume de Majorque et les terres d'Islam au XVIIe siècle», Revue d'Histoire Moderne et Contemporaine, 48 (2), pp. 123-147. <https:// doi.org/10.3917/rhmc.482.0123>

Salas Almela, Luis (2002), Colaboración y conflicto. La Capitanía General del Maro Océano y Costas de Andalucía, 1588-1660, Córdoba, Universidad de Córdoba.

Salas Almela, Luis (2006), «La agencia en Madrid del VIII duque de Medina Sidonia, 1615-1636», Hispania, 66 (224), pp. 909-958. <https://doi.org/10.3989/ hispania.2006.v66.i224.25>.

Salas Almela, Luis (2008), Medina Sidonia: el poder de la aristocracia, Madrid, Marcial Pons.

Salas Almela, Luis (2016), «Estrategias económicas señoriales y matrimonio: el comportamiento nupcial de la casa de Medina Sidonia (1492-1658)», Investigaciones Históricas: época moderna y contemporánea, 36, pp.13-39.

Saldanha de Albuquerque, Antonio de (1997), Crónica de Almançor, sultão de Marrocos (1578-1603), Lisboa, IICT.

SAncho de Sopranis, Hipólito, «Para la historia de Larache», Mauritania, vol. 24, 262, pp. 101-122.

SAnz Ayán, Carmen (2004), Estado, monarquía y finanzas. Estudios de Historia financiera en tiempos de los Austrias, Madrid, Centro de Estudios Políticos y Constitucionales.

SAnz Ayán, Carmen (2015), Un banquero en el siglo de oro. Octavio Centurión, el financiero de los Austrias, Madrid, La Esfera de los Libros.

Thompson, Irving A. A. (1981), Guerra y decadencia. Gobierno y administración en la España de los Austrias, 1560-1620, Barcelona, Crítica [edición original, 1976].

Thompson, Irving A. A. (1991), "El reinado de Felipe IV”, en Andrés-Gallego, José (coord.), Historia General de España y América, Madrid, Rialp, tomo 8, pp. 443-492.

Velázquez Gaztelu, Juan Pedro (1996), Catálogo de todas las personas ilustres de esta ciudad de Sanlúcar de Barrameda, Cádiz, ASEHA, [edición original, 1760]. 